\title{
Molecular analysis of Baylisascaris columnaris revealed mitochondrial and nuclear polymorphisms
}

Frits Franssen*, Kayin Xie, Hein Sprong and Joke van der Giessen

\begin{abstract}
Background: Baylisascaris species are intestinal nematodes of skunks, raccoons, badgers, and bears belonging to the genus Ascarididae. Oral uptake of embryonated Baylisascaris sp. eggs by a wide variety of mammals and birds can lead to visceral, ocular and neurological larva migrans. B. procyonis, the raccoon roundworm, is known to cause severe illness in intermediate hosts and in humans, whereas the skunk roundworm B. columnaris is probably less pathogenic. Skunks and raccoons are kept as pets in Europe, sometimes together with cats and dogs, living in close contact with humans. B. procyonis and B. columnaris are difficult to differentiate based on morphological criteria and molecular and phylogenetic information concerning $B$. columnaris is missing. This is the first study on the genetic characterisation of $B$. columnaris, based on mitochondrial and nuclear molecular markers.

Methods: B. columnaris worms were isolated from pet skunks, and used for molecular analysis. PCR primers targeted at mitochondrial cytochrome c oxidase 1 and 2 (CO1 and CO2), ribosomal ITS1-5.8S-ITS2 and ribosomal 285 genes were used. DNA sequences from B. columnaris, B. procyonis and B. transfuga from bears were analysed by cluster analysis.

Results: Four different multi-locus genotypes were found in B. columnaris, based on 14 single nucleotide polymorphisms (SNPS) and two insertions / deletions in CO1, CO2, ITS1-5.8S-ITS2 and 28S.

Conclusions: The genetic characteristics of $B$. columnaris show close resemblance to those of $B$. procyonis, but in contrast to $B$. procyonis, show several polymorphisms in both mitochondrial and nuclear markers. These polymorphisms could be used as a tool to differentiate B. columnaris from B. procyonis in molecular diagnostic assays, and to identify $B$. columnaris by $\mathrm{PCR}$, in addition to or replacing morphometric analysis. This might lead to more insight into the zoonotic relevance of $B$. columnaris in humans.
\end{abstract}

Keywords: Baylisascaris columnaris, Molecular characterization, Species-specific sites

\section{Background}

Baylisascaris species in raccoons (B. procyonis), skunks (B. columnaris) and badgers (B. melis) cause visceral, ocular and neural larva migrans (VLM, OLM, NLM) in a range of intermediate hosts, which serve as prey.

In the USA, the raccoon parasite B. procyonis is considered the most common cause of larva migrans syndrome in a wide range of intermediate host species and humans [1,2]. In Germany, several cases of clinical baylisascariosis have been

\footnotetext{
* Correspondence: frits.franssen@rivm.nl

National Institute for Public Health and Environment (RIVM), Center for Zoonoses and Environmental Microbiology (cZ\&O), Antonie van Leeuwenhoeklaan 9, P.O. Box 1, Bilthoven 3720 BA, The Netherlands
}

described in animal caretakers and in a boy owning a pet raccoon that was kept indoors [3-5]. There are over twenty well-documented cases of OLM and severe or even fatal neurological disorders in humans caused by B. procyonis, especially in children and young adults exhibiting pica or geophagy [1,6].

Skunks are a definitive host of B. columnaris, which like B. procyonis, causes VLM, OLM and NLM in naturally or experimentally infected rodents and rabbits, both prey of skunks [7-9]. Experimental infections showed that B. procyonis is more pathogenic to mice than $B$. columnaris, due to faster growth to $1 \mathrm{~mm}$ larval size, which correlates with the first observation of nervous symptoms in this host

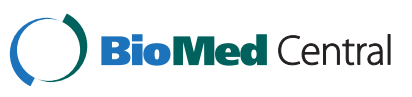


species [10]. Moreover, 2-5 larvae of B. procyonis in a single mouse brain lead to death within 25 days post infection (pi), whereas mice with $2-5$ B. columnaris larvae in their brain died between 20 and 50 days pi or later [10]. However, administration of high numbers of $B$. columnaris eggs evokes the same clinical symptoms as are seen with B. procyonis in lower numbers [2]. Skunks and raccoons are kept as pets in Europe, sometimes together with cats and dogs, living in close contact with humans. Dogs can act as both paratenic and definitive host for B. procyonis [11], but no experimental or natural infections of cats with B. procyonis were documented $[2,12]$.

Diagnosis in the final host is based on morphometric identification of B. procyonis and B. columnaris individual worms or faecal eggs, although identification to species level is often hampered by diversity in size and developmental stage and the vast majority of worms being female.

Diagnosis of larva migrans caused by ascarid nematodes in humans mainly depends on serological or histochemical assays, which often have a low level of specificity. Additional serological techniques like western blot and recombinant antigen-based BpRAG1 ELISA showed higher ability to discriminate between B. procyonis and Toxocara canis in patients with larva migrans syndrome $[13,14]$, but tools to discriminate between Baylisascaris species are not available, which makes it difficult to assess the potential public health relevance of $B$. columnaris.

Molecular studies have been published concerning mitochondrial and nuclear markers of $B$. procyonis, B. schroederi and B. transfuga [15-18]. The phylogenetic relationship between ascarid nematodes originating mainly from wildlife host species has been studied, including B. procyonis, B. schroederi, B. transfuga and $B$. ailuri [19]. Analysis of 12 protein encoding genes showed that $B$. procyonis is closely related to, but distinct from other Baylisascaris species (B. ailuri, B. transfuga and B. schroederi) [20], but B. columnaris was not included in any of these studies.

In this paper, we studied nuclear and mitochondrial markers, based on the mitochondrial genes cytochrome c oxidase 1 and 2 (CO1 and $\mathrm{CO} 2$ ) and the ribosomal ITS1, ITS2, $5.8 \mathrm{~S}$ and $28 \mathrm{~S}$ genes of B. columnaris and $B$. procyonis. We show the close genetic relationship between these two Baylisascaris species and in addition, we identified four different multilocus types of B. columnaris, based on 14 single nucleotide polymorphisms (SNPs) in aforementioned genes and differences in G-A tandem repeats in ITS2. Based on these results, we conclude that B. columnaris and B. procyonis are closely related, but can be discriminated. Therefore, tools can be developed to study the potential zoonotic relevance of B. columnaris in humans in more detail.

\section{Methods}

\section{Animals and parasites}

From 2011 to 2012, parasites that were expelled from skunks after pyrantel pamoate treatment were collected at privately owned shelters in The Netherlands. The collected parasites were sent to our institute in $70 \%$ ethanol and identified morphologically using taxonomic characteristics as defined previously [21,22]. Subsequently, a small part (2-4 mm) from the mid-section of each parasite was isolated and transferred to $2 \mathrm{ml}$ tubes containing $0.1 \mathrm{~mm}$ silica beads (Lysis matrix B, MP Biochemicals, Eindhoven, The Netherlands). These samples were stored at $-20^{\circ} \mathrm{C}$ until further use.

Dr. Kevin Kazacos (Purdue University, West Lafayette, Indiana, USA) kindly provided eight ethanol-preserved B. procyonis worms from North American raccoons. Dr. Rebecca Davidson (Norwegian Veterinary Institute, Oslo, Norway) kindly provided twenty-three Baylisascaris worms from raccoons kept in Norway. Dr. Herman Cremers (Utrecht University, The Netherlands) provided $B$. procyonis, B. columnaris and B. transfuga adult worms. Additionally, $B$. transfuga parasites were isolated from a brown bear and a sloth bear, both zoo animals. Details on the parasites used in this study are shown in Table 1.

\section{DNA isolation}

DNA was extracted from worm tissue using the Qiagen DNeAsy Blood \& Tissue Kit (Qiagen Benelux BV, Venlo, The Netherlands) according to the manufacturer's instructions. The protocol was slightly modified by addition of a tissue disruption step before and after proteinase $\mathrm{K}$ incubation, using a bead-beater for $45 \mathrm{~s}$ at $6.5 \mathrm{~m} / \mathrm{s}^{2}$ (Fastprep ${ }^{\mathrm{TM}}$ FP 120, Thermo Electron Corporation, Milford, MA, USA). The isolated DNA was eluted in $10 \mathrm{mM}$ Tris- $\mathrm{HCl}$ and stored at $-20^{\circ} \mathrm{C}$ until further use.

\section{PCR primers}

A primer pair targeted at the mitochondrial $\mathrm{CO} 1$ was used according to Bowles et al. (1992) [23]. Furthermore, primers targeting the $\mathrm{CO} 2$ gene were designed based on the consensus sequence of $B$. columnaris [Genbank accession number FJ357429], B. procyonis [AF179908] and B. transfuga [AF 179909, HM594949 and FJ890507].

Primer pairs targeted at ITS1-5.8S-ITS2 ribosomal DNA were designed based on the ribosomal consensus sequences of B. transfuga [JN617990, AB571304], B. schroederi [JN210911, JN210912] and B. procyonis [AB053230, AJ007458]. PCR primers for 28S rDNA were designed based on the consensus sequence of B. transfuga [HM594950, HM594951 and U94754] and B. procyonis [U94753]. Primer sequences are shown in Table 2. 
Table 1 Baylisascaris worm origin and gender

\begin{tabular}{|c|c|c|c|c|c|c|c|}
\hline Species & \#Worms & Male & Female & Juvenile & Host name & Host gender & Source \\
\hline B. columnaris & 19 & 5 & 10 & 4 & S and/or I 1 & $M / F^{2}$ & Shelter $\mathrm{H}(\mathrm{NL})$ \\
\hline B. columnaris & 1 & - & - & - & J & M & Shelter K (NL) \\
\hline B. columnaris & 5 & 3 & 2 & 0 & DD & M & Shelter K (NL) \\
\hline B. columnaris & 10 & 2 & 5 & 3 & N & $\mathrm{F}$ & Shelter K (NL) \\
\hline B. columnaris & 31 & 11 & 20 & 0 & V & M & Shelter K (NL) \\
\hline B. columnaris & 4 & 0 & 4 & 0 & $P$ & $\mathrm{~F}$ & Shelter P (NL) \\
\hline B. columnaris & 19 & 1 & 18 & 0 & C & F & Shelter P (NL) \\
\hline B. columnaris & 30 & 11 & 19 & 0 & A & $\mathrm{F}$ & Shelter P (NL) \\
\hline Totals: & 119 & 33 & 78 & 7 & - & - & - \\
\hline B. procyonis & 8 & 2 & 6 & 0 & ns & ns & (USA) \\
\hline B. procyonis & 4 & 1 & 3 & 0 & 652 & ns & (Norway) \\
\hline B. procyonis & 7 & 2 & 5 & 0 & 653 & ns & (Norway) \\
\hline B. procyonis & 10 & 3 & 7 & 0 & 654 & ns & (Norway) \\
\hline B. procyonis & 2 & 0 & 1 & 1 & 655 & ns & (Norway) \\
\hline Totals: & 31 & 8 & 22 & 1 & - & - & 2 \\
\hline
\end{tabular}

${ }^{1}$ Origin of worm uncertain due to lack of animal isolation possibilities; these worms were excluded from further molecular analyses. ${ }^{2}$ Gender of S: male, I: female. ns: not stated.

\section{PCR conditions}

All PCR reactions were carried out in $50 \mu$ final volume containing $3 \mu \mathrm{l}$ genomic DNA, $0.5 \mu \mathrm{l}$ of each forward and reverse primer $(50 \mu \mathrm{M}$ stock) and $25 \mu \mathrm{l}$ of Qiagen HotstarTaq Plus polymerase master mix (Qiagen NV, Venlo, The Netherlands). The final reaction volume was adjusted to $50 \mu \mathrm{l}$ with sterile demineralised water. The PCR amplification of $\mathrm{CO} 1$ and $\mathrm{CO} 2$ was performed using the following conditions: denaturation at $95^{\circ} \mathrm{C}$ for $15 \mathrm{~min}$, followed by 35 cycles of $1 \mathrm{~min}$ denaturation at $95^{\circ} \mathrm{C}$, $1 \mathrm{~min}$ annealing at $45^{\circ} \mathrm{C}, 1: 15 \mathrm{~min}$ elongation at $72^{\circ} \mathrm{C}$, followed by a final extension step of $7 \mathrm{~min}$ at $72^{\circ} \mathrm{C}$.

The PCR amplification of ITS1-5.8S-ITS2 and 28S rDNA was performed under the following conditions: $95^{\circ} \mathrm{C}$ for $15 \mathrm{~min}$, followed by 40 cycles of $95^{\circ} \mathrm{C}$ for $30 \mathrm{~s}$,

Table 2 Overview of the PCR primers used in this study

\begin{tabular}{ll}
\hline Primer name & Primer sequence \\
\hline CO1 F & 5'-TTाTTGGGCATCCTGAGGTTTAT-3' \\
CO1 R & 5'-TAACGACATAACATAATGAAAATG-3' \\
CO2 F & 5'-AATTTTAATTGTAGTCTTTGTTTGG-3' \\
CO2 R & 5'-CTATGATTAGCACCACAAATC-3' \\
ITS1-5.8S-ITS2 F & 5'-ATAGTGAGTTGCACACTAATGT-3' \\
ITS1-5.8S-ITS2 R & 5'-TTATATGCTTAAATTCAGCGGG-3' \\
ITS2 F & 5'-GCCATTTATGAATTTCAACATGG-3' \\
ITS2 R & 5'-AGTTATATGCTTAAATTCAGCGG-3' \\
$28 S$ rDNA F & 5'-CGAGGATTCCCTTAGTAACT-3' \\
$28 S$ rDNA R & 5'-TCGGATAGGTGGTCAACG-3' \\
\hline
\end{tabular}

Primer sequences for PCR amplification of mitochondrial and nuclear markers of B. columnaris, B. procyonis and B. transfuga. $50^{\circ} \mathrm{C}$ for $30 \mathrm{~s}, 72^{\circ} \mathrm{C}$ for $1: 15 \mathrm{~min}$ and $72^{\circ} \mathrm{C}$ for $7 \mathrm{~min}$. PCR products were analysed on $1.5 \%$ agarose gel.

\section{DNA sequencing of amplified PCR products}

PCR amplicons were purified using standard procedures (ExoSAP-IT ${ }^{\circledR}$, Affymetrix, Cleveland, Ohio, USA). Sequence PCR reactions on both strands were carried out in $20 \mu \mathrm{l}$ final volume containing $3 \mu \mathrm{l}$ of amplicate, $7 \mu \mathrm{l}$ sequence buffer, $1 \mu \mathrm{l}$ of Big Dye Terminator and $1 \mu \mathrm{l}$ of each PCR primer. The sequence PCR was performed under the following conditions: $95^{\circ} \mathrm{C}$ for $1 \mathrm{~min}$, followed by 25 cycles of $96^{\circ} \mathrm{C}$ for $10 \mathrm{~min}, 50^{\circ} \mathrm{C}$ for $5 \mathrm{~min}$ and finally $60^{\circ} \mathrm{C}$ for $4 \mathrm{~min}$. Trace files of sequences were generated on an automated ABI sequencer at the Institute's sequence facility.

\section{Sequence analysis and phylogeny}

Obtained DNA sequences were aligned, analysed with BioNumerics version 6.6 (Applied Maths NV, Sint-Martens -Latem, Belgium) and compared with DNA sequences present in Genbank, after subtraction of the primer sequences. Phylogenetic analysis was performed by Maximum Likelihood inference using 500 bootstraps [24,25].

\section{Results}

\section{Animals and parasites}

In total, 119 B. columnaris worms were isolated from seven skunks (Table 1). Among these are five stray animals (D, N, $\mathrm{V}, \mathrm{C}$ and A). Worm body size varied, ranging from 3-4 centimetres for adult males and young females, to a maximum of 14 centimetres for adult females. All worms were morphologically identified as Baylisascaris sp., based on the 
absence of cervical alae in adult worms, the morphology and size of intra-uterine eggs (76.7 \pm 5.1 by $64.6 \pm 5.8 \mu \mathrm{m}$, $\mathrm{n}=10$ ) that were isolated from gravid females, the morphology and size of faecal eggs $(72.5 \pm 4.1$ by $63.2 \pm 7.5 \mu \mathrm{m}$, $\mathrm{n}=10$ ) in coprological examination, the typical ascarid mouthparts with three developed lips (one dorsal and two subventral), the presence of precloacal genital papillae, two spicules and perianal roughened patches in adult males. Species identification was carried out using differentiating features as defined by Sprent (1968) [22], which can discriminate between different Baylisascaris species. Figure 1 shows characteristic morphological features of $B$. procyonis (A and D), and B. columnaris (B, E and C, F) isolates of this present study. Figure $1 G$ zooms in on typical male B. columnaris features, being perianal roughened patches of more or less equal width and the spike-shaped terminal end of the tail.

\section{PCR and sequence analysis}

Mitochondrial CO1 amplicons (413 bp) were obtained from forty-three individual $B$. columnaris isolates, nineteen $B$. procyonis and two $B$. transfuga isolates. $\mathrm{CO} 2$ amplicons measured $483 \mathrm{bp}$ and were obtained from thirty-eight individual $B$. columnaris isolates, ten $B$. procyonis and one $B$. transfuga isolate. $\mathrm{CO} 2$ sequence alignment of fifteen B. columnaris isolates (represented by Figure $1 \mathrm{C}$ and $1 \mathrm{~F}$ )
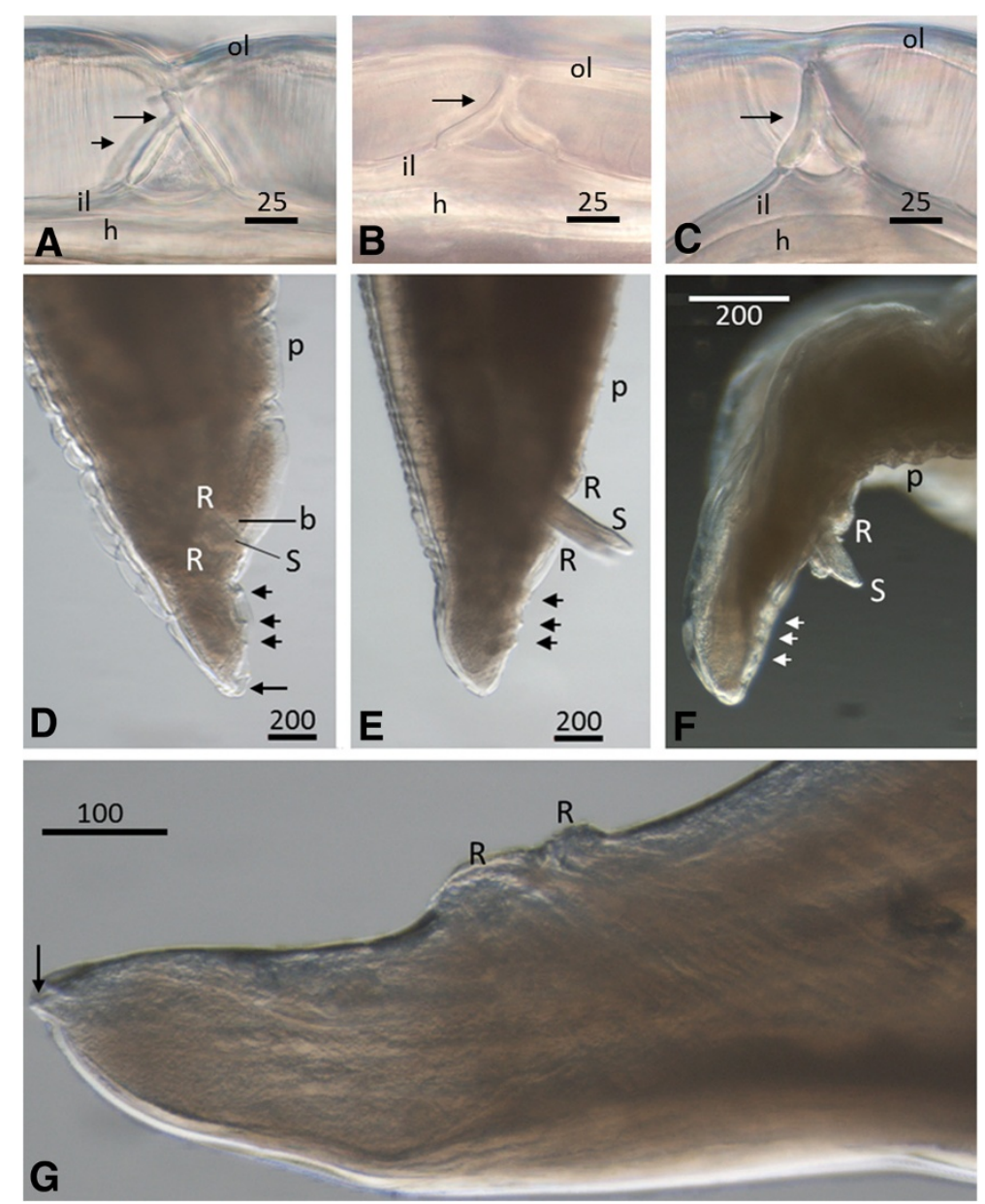

Figure 1 Morphological differentiation of Baylisascaris procyonis (A, D) from B. columnaris (B, E and C, F). A - C: Unstained cross section of lateral cuticle through anterior end of adult female worms (about 10 centimetres in length), 6 millimetres behind mouthparts and rotated $90^{\circ}$ in plane. Cross section in lateral view showing outer cuticle lining (ol), inner cuticle lining (il), hypodermis (h) and cervical support in hyaline layer (arrow). Sometimes, cervical supports of the deeper layer are visible, though not in focus (arrowhead). A: Female B. procyonis (isolate Bp9), wide arch-like cervical support B: Female B. columnaris (K19), narrow A-like support C: Female B. columnaris (K10), narrow A-like support. D - F: Posterior end of males showing pre-cloacal papillae (p), pericloacal roughened areas (R) with rounded posterior margin in figure $\mathbf{E}$, bare pre-cloacal rim (b), extruded spicules (S, not in focus in $\mathbf{D}$ ), post- cloacal papillae (short arrow), terminal part of tail knob (D) or spike (G; E and $\mathbf{F}$ out of focus) shaped (long arrow). D: Ventrolateral view of B. procyonis (Bp19), precloacal roughened patch $42 \mu \mathrm{m}$ and postcloacal patch $72 \mu \mathrm{m}$ in width. E: Lateral view of B. columnaris (K23), F: Lateral view of B. columnaris (K22). G: Lateral view of posterior end of male B. columnaris (P27), showing spike shaped posterior end of the tail (arrow) and pericloacal roughened patches in close up; precloacal patch (right) $63 \mu \mathrm{m}$ and postcloacal patch (left) $79 \mu \mathrm{m}$ in width. Scale bars in $\mu \mathrm{m}$. See Table 3 for molecular classification of isolate numbers. 
revealed $100 \%$ CO2 sequence homology with a partial B. columnaris $\mathrm{CO} 2$ sequence present in Genbank. This sequence was derived of a parasite that was isolated from a road-killed skunk from Indiana, USA [FJ357429]. The other twenty-three B. columnaris isolates (represented by Figure $1 B, 1 E$ and $1 G$ ) showed $99.4 \%$ similarity with both B. columnaris [FJ357429] and B. procyonis [JF951366].

Alignment of the $413 \mathrm{bp}$ CO1 sequences revealed six single nucleotide polymorphisms (SNPs), three of which were homologous between B. columnaris isolates, but differed from B. procyonis (nt positions 61, 91 and 259) (Table 3). Alignment of the $483 \mathrm{bp} \mathrm{CO} 2$ sequences showed four additional SNPs, one of which was homologous between $B$. columnaris isolates but different from $B$. procyonis (nt position 66) (Table 3). In silico translation of the open reading frames of $\mathrm{CO} 1$ and $\mathrm{CO} 2$ resulted in 137 and 161 amino acids without stop codons respectively.

Ribosomal ITS1-5.8S-ITS2 amplicons (644 or 647 bp) were obtained from fifteen $B$. columnaris isolates, twelve $B$. procyonis isolates $(650 \mathrm{bp})$ and two $B$. transfuga isolates $(630 \mathrm{bp})$. Sequence alignment revealed an insertion as compared to B. procyonis in the ITS1 gene (nt 1-228) at nucleotide position 152 and a SNP at nt 201. The sequence of 5.8S rDNA (nt 229-385) was homologous between $B$. columnaris and $B$. procyonis isolates, but differed from $B$. transfuga (nt 230, 337 and 346) (Table 4). In the ITS2 gene region (nt 386 and further), a tandem repeat was found commencing at nucleotide position 526 and containing a number of G-A inserts varying with Baylisascaris species. Nine G-A tandem repeats were identified for B. procyonis, which was corroborated by comparison with Genbank accession number AB051231. Two genotypes were found in B. columnaris: one with six G-A tandem repeats and another with seven. B. transfuga had only two G-A tandem repeats, which was corroborated by Genbank accession number EU642819, and was different from the tandem repeat in B. schroederi [JN210911 and JN210912] (Figure 2).

Nuclear 28S rDNA amplicons (718 bp) were obtained from fifteen B. columnaris, eight B. procyonis and two $B$. transfuga isolates. Sequence alignment revealed an SNP for B. procyonis on nucleotide position 61, (either C or T). A polymorphism at nucleotide position 499 for B. columnaris ( $\mathrm{G}$ or $\mathrm{C}$ ) was found, which coincided with six or seven G-A tandem repeats on the ITS2 gene sequence (Table 4). Combination of mitochondrial and nuclear sequence data resulted in four multi-locus genotypes (I to IV, Tables 3 and 4).

Sequence data for B. columnaris, B. procyonis and B. transfuga obtained in this study were deposited in Genbank [accession numbers KC543466-KC543471 (28S), KC543472-KC543477 (CO1), KC543478-KC543483 (CO2) and KC543484-KC543489 (ITS1-5.8S-ITS2)].

\section{Phylogenetic analysis}

To confirm the relative position of $B$. columnaris within the group of ascarid nematodes, a maximum likelihood (ML) tree was inferred from CO1 sequences of $B$. procyonis, B. columnaris and B. transfuga (this study) and of other ascarid nematodes present in Genbank [AB591801, AB591802, AB591803, AF182297, AJ920057, AJ920062, AJ920064, AJ920063, EU628682, EU628685, EU628686 and HM594948]. A CO1 sequence of Heterakis isolonche [FJ009625] was used as out-group (Figure 3).

The inferred ML tree of concatenated CO1 and CO2 sequences shows two B. columnaris clusters (type 1 and 2, 15 isolates, and type 3 and 4, 23 isolates), which are separated from $B$. procyonis, supported by high bootstrap values

Table 3 Multi-locus types of Baylisascaris columnaris mitochondrial genes

\begin{tabular}{|c|c|c|c|c|c|c|c|c|c|c|c|c|c|}
\hline \multirow{2}{*}{$\begin{array}{l}\text { Worm } \\
\text { isolates } \\
\end{array}$} & \multirow{2}{*}{$\begin{array}{c}\text { Worm } \\
\text { gender }\end{array}$} & \multirow{2}{*}{$\begin{array}{c}\text { Skunk } \\
\text { ID }\end{array}$} & \multicolumn{6}{|c|}{ CO1 fragment } & \multicolumn{4}{|c|}{ CO2 fragment } & \multirow{2}{*}{$\begin{array}{c}\text { ML } \\
\text { type }\end{array}$} \\
\hline & & & 59 & 61 & 79 & 91 & 229 & 259 & 66 & 117 & 280 & 480 & \\
\hline $\mathrm{K} 14, \mathrm{~K} 16$ & $\mathrm{~F}$ & $\mathrm{~N}$ & $\mathrm{~T}$ & G & $C$ & A & G & G & G & A & C & G & I \\
\hline $\mathrm{K} 22, \mathrm{~K} 24$ & M & V & $\mathrm{T}$ & G & $C$ & A & G & G & G & A & C & G & I \\
\hline $\mathrm{K} 15, \mathrm{~K} 10$ & $\mathrm{~F}$ & $\mathrm{~N}$ & $\mathrm{~T}$ & G & $C$ & A & G & G & G & A & C & G & $\|$ \\
\hline K21 & M & V & $\mathrm{T}$ & G & $C$ & A & G & G & $G$ & A & C & G & $\|$ \\
\hline K17 & $\mathrm{F}$ & V & $C$ & G & $T$ & A & A & G & G & G & $\mathrm{T}$ & $\mathrm{T}$ & III \\
\hline K23 & M & V & $C$ & G & $\mathrm{T}$ & A & A & G & $G$ & G & $\mathrm{T}$ & $\mathrm{T}$ & III \\
\hline P24 & $\mathrm{F}$ & $P$ & $C$ & G & $\mathrm{T}$ & A & A & G & G & G & $\mathrm{T}$ & $\mathrm{T}$ & III \\
\hline P27 & M & A & $C$ & G & $\mathrm{T}$ & A & A & G & G & G & $\mathrm{T}$ & $\mathrm{T}$ & III \\
\hline K19, 20 & $\mathrm{~F}$ & V & $C$ & G & $T$ & A & A & G & G & G & $\mathrm{T}$ & $\mathrm{T}$ & IV \\
\hline \multicolumn{3}{|c|}{ B. procyonis isolates } & $\mathrm{T}$ & A & $\mathrm{T}$ & G & A & A & A & A & $\mathrm{T}$ & $\mathrm{T}$ & - \\
\hline \multicolumn{3}{|c|}{ B. transfuga isolates } & $\mathrm{T}$ & A & $\mathrm{T}$ & G & $\mathrm{T}$ & G & G & A & $\mathrm{T}$ & G & - \\
\hline
\end{tabular}

Four different genotypes of Baylisascaris columnaris were found: two variants of mitochondrial genes $\mathrm{CO} 1$ and $\mathrm{CO} 2$, and two variants of nuclear genes ITS1-5.8S-ITS2 and 28S rDNA. These variants were linked two by two. Neither recombinations of mitochondrial type 1 and 2, nor recombinations of nuclear type 1 and 2 occurred in individual worms. No preference of any combination for worm gender was observed. 
Table 4 Multi-locus types of Baylisascaris columnaris ribosomal genes

\begin{tabular}{|c|c|c|c|c|c|c|c|c|c|c|c|}
\hline \multirow{2}{*}{$\begin{array}{l}\text { Worm } \\
\text { isolates }\end{array}$} & \multirow{2}{*}{$\begin{array}{l}\text { Worm } \\
\text { gender }\end{array}$} & \multirow{2}{*}{$\begin{array}{c}\text { Skunk } \\
\text { ID }\end{array}$} & \multicolumn{2}{|c|}{ ITS1 } & \multicolumn{3}{|c|}{$5.8 \mathrm{~S}$} & \multirow{2}{*}{$\begin{array}{l}\text { ITS2 } \\
527\end{array}$} & \multicolumn{2}{|c|}{$28 \mathrm{~S}$} & \multirow{2}{*}{$\begin{array}{c}M L \\
\text { type }\end{array}$} \\
\hline & & & 152 & 201 & 230 & 337 & 346 & & 49 & 487 & \\
\hline $\mathrm{K} 14, \mathrm{~K} 16$ & $\mathrm{~F}$ & $\mathrm{~N}$ & - & $T$ & G & $T$ & $C$ & 6 & $C$ & $G$ & 1 \\
\hline K22, K24 & M & V & - & T & G & $\mathrm{T}$ & C & 6 & C & G & I \\
\hline $\mathrm{K} 15, \mathrm{~K} 10$ & $\mathrm{~F}$ & $\mathrm{~N}$ & A & T & G & T & C & 7 & C & C & $\|$ \\
\hline K21 & M & V & A & T & G & T & C & 7 & C & $C$ & $\|$ \\
\hline K17 & $\mathrm{F}$ & V & - & T & G & T & C & 6 & C & G & III \\
\hline K23 & M & V & - & T & G & $\mathrm{T}$ & C & 6 & C & G & III \\
\hline P24 & $\mathrm{F}$ & P & - & $\mathrm{T}$ & G & $\mathrm{T}$ & $C$ & 6 & C & G & III \\
\hline P27 & M & A & - & $\mathrm{T}$ & G & $\mathrm{T}$ & C & 6 & C & G & III \\
\hline K19, 20 & $F$ & V & A & T & G & T & $C$ & 7 & C & C & IV \\
\hline \multicolumn{3}{|c|}{ B. procyonis isolates } & - & C & G & $\mathrm{T}$ & C & 9 & $\mathrm{~T} / \mathrm{C}$ & C & - \\
\hline \multicolumn{3}{|c|}{ B. transfuga isolates } & A & $\mathrm{T}$ & $\mathrm{T}$ & C & $\mathrm{T}$ & - & C & $\mathrm{T}$ & - \\
\hline
\end{tabular}

The numbers refer to nucleotide positions of the SNP in the gene sequence alignments. For ITS2, the number of G-A tandem repeats from nucleotide position 526 onward is shown. The characteristics of B. procyonis and B. transfuga are shown for reference. (F: female, M: male, ML: multi-locus).

(Figure 4A). The B. columnaris intra-species difference based on concatenated $\mathrm{CO} 1$ and $\mathrm{CO} 2$ sequences was $0.68 \%$, whereas the inter-species differences with B. procyonis were $0.71 \%$ and $0.91 \%$ respectively. An inferred ML tree from concatenated ribosomal markers (ITS1-5.8SITS2 and 28S) again revealed two B. columnaris groups which diverge from $B$. procyonis (Figure $4 \mathrm{~B}$ ), but are not identical to the ML shown in Figure 4A. However, this is based on only three SNPs and one nucleotide insert, which is too few to obtain a reliable differentiation.

\section{Discussion}

This is the first study showing the close relatedness based on molecular data and phylogenetic analysis of $B$. procyonis and B. columnaris, which was isolated from pet skunks. B. columnaris is an exotic species in Europe, which is imported together with its final host M. mephitis. Evaluation of the public health relevance of $B$. columnaris is hampered by the fact that molecular data and description of clinical manifestations in humans are absent in the literature, despite recent publications

B. procyonis $\mathrm{Bp} 1$
B. procyonis $\mathrm{Bp} 2$
B. procyonis $\mathrm{Bp} 3$
B. procyonis $\mathrm{Bp4}$
B. procyonis $\mathrm{Bp5}$
B. procyonis $\mathrm{Bp} 6$
B. procyonis $\mathrm{Bp} 7$
B. procyonis $\mathrm{Bp} 8$
B. procyonis $\mathrm{Bp9}$
B. procyonis $\mathrm{Bp} 10$
B. procyonis $\mathrm{Bp} 11$
B. procyonis $\mathrm{AB} 051231$
B. columnaris $\mathrm{K} 10$
B. columnaris $\mathrm{K} 15$
B. columnaris $\mathrm{K} 20$
B. columnaris $\mathrm{K} 3$
B. columnaris $\mathrm{K} 14$
B. columnaris $\mathrm{K} 17$
B. columnaris $\mathrm{K} 23$
B. columnaris $\mathrm{K} 24$
B. columnaris $\mathrm{K} 4$
B. columnaris $\mathrm{K} 5$
B. columnaris K6
B. columnaris K7
B. columnaris $\mathrm{K} 9$
B. columnaris $\mathrm{P} 24$
B. columnaris $\mathrm{P} 27$
B. schroederi JN210911
B. schroederi $\mathrm{JN} 210912$
B. transfuga $\mathrm{Bt1}$
B. transfuga $\mathrm{B} 2$
B. transfuga $\mathrm{AB} 571304$



Figure 2 G-A tandem repeats with different length on the ITS2 gene. B. procyonis has 9 G-A tandem repeats on the ITS2 gene, where B. columnaris has two tandem repeats of different length, six or seven G-A repeats. $B$. transfuga has a much shorter $\mathrm{G}$-A tandem repeat sequence, which is one nucleotide shorter and different from the tandem repeat in B. schroederi. 


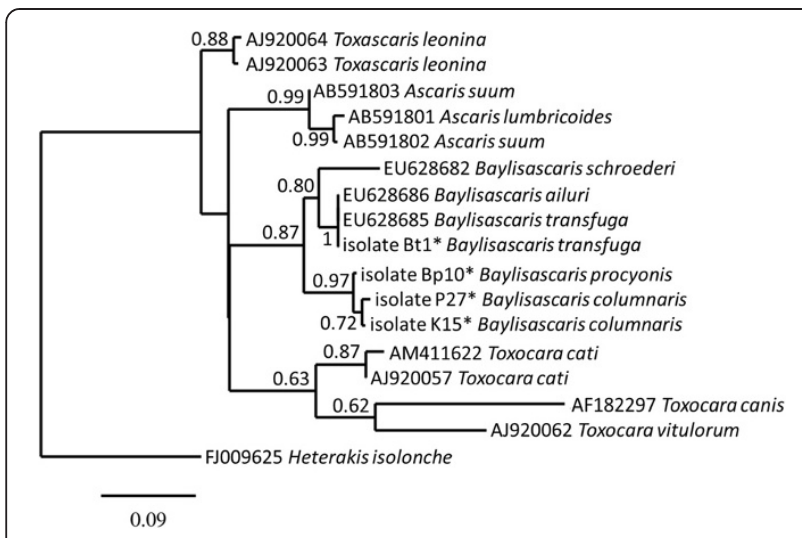

Figure 3 Relative position of Baylisascaris in the genus Ascarididae. ML of $\mathrm{CO} 1$ gene sequences of ascarid nematode species available in Genbank and new isolates (this study). The consensus $\mathrm{CO} 1$ gene sequence of the $B$. transfuga isolates shows 100\% identity with sequences from Genbank. CO1 gene sequences of $B$. procyonis and $B$. columnaris isolates separate from other ascarid species and from each other with high bootstrap support (500 bootstraps). ${ }^{*}$ This study, see also Figure 2 and Table 3 .

concerning molecular characterization of various Baylisascaris species [17-20]. So far, only a single (partial) sequence of the mitochondrial $\mathrm{CO} 2$ gene of $B$. columnaris was available in Genbank at the time [accession number FJ357429] [26].

The present study corroborates the very close relationship between $B$. procyonis from raccoons and B. columnaris from skunks, based on morphological, molecular and phylogenetic analyses.

The combined mitochondrial and ribosomal DNA sequences of $B$. columnaris yielded four multi-locus genotypes, which could be retrieved from one single host

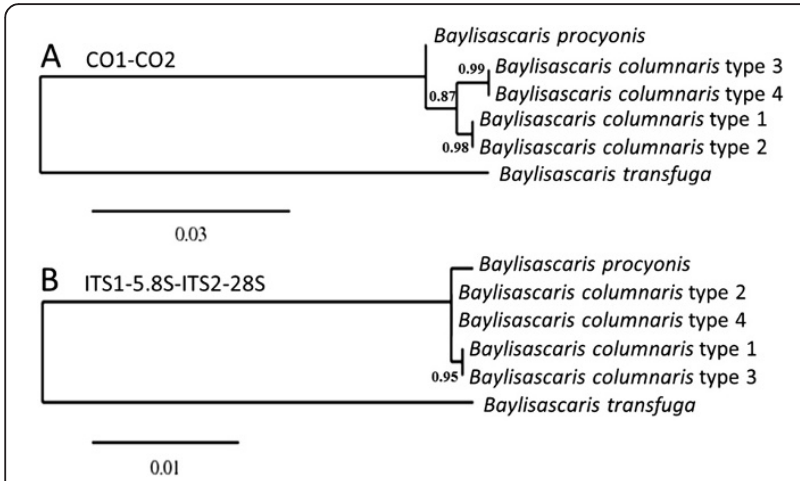

Figure 4 Maximum likelihood trees inferred from Baylisascaris sp. mitochondrial and ribosomal gene sequences. A: ML of concatenated mitochondrial markers $\mathrm{CO} 1$ and $\mathrm{CO} 2$ shows a clear separation between $B$. procyonis and $B$. columnaris, which in turn is divided into two different groups. B: ML of concatenated ribosomal markers ITS1-5.8S-ITS2 and 28S again shows two B. columnaris groups, which separate from $B$. procyonis, although to a lesser extent, due to the number of G-A repeats $(9,7$ and 6$)$ as most important difference (see also Table 4). animal. Other individual skunks carried either one or two B. columnaris multi-locus genotypes. Since we analysed single worms from individual animals, we were able to show the presence of two genotypes of mitochondrial $\mathrm{CO} 1$ and $\mathrm{CO} 2$, indicating separate maternal lineages and possibly different geographical origins of the B. columnaris parasites.

The close relationship with $B$. procyonis both on mitochondrial and nuclear markers, and the relative distance between the two B. columnaris mitochondrial variants, initially raised the question whether these genuinely were two genotypes of one species, taking into account that their skunk hosts had artificially been introduced into a new environment and the history of most animals was not known. However, all four multi-locus genotypes could be isolated simultaneously from one individual skunk and the recombination of mitochondrial with nuclear subtypes showed that there is interbreeding between the two phylogroups of $B$. columnaris, supporting that these are indeed one species.

The origin of the distinct genotypes identified in B. columnaris are unknown, but may also reflect two (ancient) subpopulations in the skunk host of $B$. columnaris in North America [27]. B. columnaris $\mathrm{CO} 2$ sequences of both multi-locus sequence type (MLST) I and MLST II are $100 \%$ homologous to that of B. columnaris isolated from a skunk in Indiana, where $75 \%$ of skunks is of the East phylogroup [27].

B. procyonis is considered the most common cause of larva migrans syndrome in a wide range of intermediate host species and humans [1,2], and several cases of clinical baylisascariosis have also been described in humans in Europe [3-5]. However, since diagnostic tools are lacking, it is not known whether B. columnaris could cause larva migrans in humans. As serological assays do not discriminate between Baylisascaris species as mentioned before, the molecular data presented in this study might be used to design molecular diagnostic assays, to evaluate the public health relevance of $B$. columnaris. Moreover, these data might provide tools to monitor introduction and prevalence of these exotic species in wildlife.

\section{Conclusions}

This is the first study presenting molecular data and phylogenetic analysis of $B$. columnaris. The genetic characteristics presented in this study showed a close genetic resemblance of $B$. procyonis and B. columnaris. Moreover, the two Baylisascaris species can be distinguished using species-specific sites as described in this study, which could be used in PCR-based assays to study the public health relevance of this parasite. 


\section{Competing interests}

The authors declare that they do not have competing interests.

\section{Authors' contributions}

FF was involved in collecting and identifying the nematodes, primer design, molecular lab work, phylogenetic analysis and writing the manuscript. KX was involved in primer design, molecular lab work, analyses of the molecular data and writing the manuscript. HS had an advising role in molecular and phylogenetic analysis and contributed to writing of the manuscript. JvdG arranged funding and initiated the study design, supervised the practical work and contributed to writing of the manuscript. All authors read and approved the manuscript.

\section{Acknowledgements}

We would like to thank Dr. Kevin Kazacos, Dr. Rebecca Davidson and Dr. Herman Cremers for providing Baylisascaris worms. We also thank Jeroen Roelfsema, Titia Kortbeek, Kim Bensdorp and Hennie Braak for their valuable help. The authors are grateful to the journal's reviewers for their constructive criticism.

Received: 20 December 2012 Accepted: 24 April 2013

Published: 29 April 2013

\section{References}

1. Gavin PJ, Kazacos KR, Shulman ST: Baylisascariasis. Clin Microbiol Rev 2005, 18:703-718.

2. Kazacos KR: Baylisascaris procyonis and related species. In Parasitic Diseases of wild mammals Ames lowa: lowa State University Press. Edited by Samuel WM, Pybus MJ, Kocan AA. ; 2001:301-341.

3. Kuchle M, Knorr HL, Medenblik-Frysch S, Weber A, Bauer C, Naumann GO: Diffuse unilateral subacute neuroretinitis syndrome in a German most likely caused by the raccoon roundworm, Baylisascaris procyonis. Graefes Arch Clin Exp Ophthalmol 1993, 231:48-51.

4. F J, Conraths CB, Josefine Cseke und H Laube: Arbeitsplatzbedingte Infektionen des Menschen miet dem Waschbärenspulwurm Baylisascaris procyonis. Arbeitsmedizin Socialmedizin Umwelmedizin 1996, 31:13-17.

5. Bauer C: Baylisascariosis-Infections of animals and humans with 'unusual' roundworms. Vet Parasitol 2013, 193(4):404-412. doi:0.1016/j. vetpar.2012.12.036. Epub 2012 Dec 27.

6. Bauer C: Baylisascariosis (Baylisascaris procyonis) - a rare parasitic zoonosis in Europe. Berl Munch Tierarztl Wochenschr 2011, 124:465-472.

7. Sprent JF: On the migratory behavior of the larvae of various Ascaris species in white mice. I. Distribution of larvae in tissues. J Infect Dis 1952, 90:165-176.

8. Nettles VF, Davidson WR, Fisk SK, Jacobson HA: An epizootic of cerebrospinal nematodiasis in cottontail rabbits. J Am Vet Med Assoc 1975, 167:600-602.

9. Church EM, Wyand DS, Lein DH: Experimentally induced cerebrospinal nematodiasis in rabbits (Oryctolagus cuniculus). Am J Vet Res 1975, 36:331-335.

10. Tiner JD: The migration, distribution in the brain, and growth of ascarid larvae in rodents. J Infect Dis 1953, 92:105-113.

11. Park SY, Glaser C, Murray WJ, Kazacos KR, Rowley HA, Fredrick DR, Bass N: Raccoon roundworm (Baylisascaris procyonis) encephalitis: case report and field investigation. Pediatrics 2000, 106:E56.

12. Miyashita M: Prevalence of Baylisascaris procyonis in raccons in Japan and experimental infections of the worm to laboratory animals [in Japanese]. J Urban Living Health Assoc 1993, 37:137-151. cited in: Kazacos K. R. (2001) Baylisascaris procyonis and related species.

13. Dangoudoubiyam S, Kazacos KR: Differentiation of larva migrans caused by Baylisascaris procyonis and Toxocara species by Western blotting. Clin Vaccine Immunol 2009, 16:1563-1568.

14. Dangoudoubiyam S, Vemulapalli R, Ndao M, Kazacos KR: Recombinant antigen-based enzyme-linked immunosorbent assay for diagnosis of Baylisascaris procyonis larva migrans. Clin Vaccine Immunol 2011, 18:1650-1655.

15. Xie Y, Zhang Z, Niu L, Wang Q, Wang C, Lan J, Deng J, Fu Y, Nie H, Yan N, et al: The mitochondrial genome of Baylisascaris procyonis. PLOS One 2011, 6:e27066.

16. Lin Q, Li HM, Gao M, Wang XY, Ren WX, Cong MM, Tan XC, Chen CX, Yu SK, Zhao GH: Characterization of Baylisascaris schroederi from Qinling subspecies of giant panda in China by the first internal transcribed spacer (ITS-1) of nuclear ribosomal DNA. Parasitol Res 2012, 110:1297-1303.

17. Zhao GH, Li HM, Ryan UM, Cong MM, Hu B, Gao M, Ren WX, Wang XY Zhang SP, Lin Q, et al: Phylogenetic study of Baylisascaris schroederi isolated from Qinling subspecies of giant panda in China based on combined nuclear $5.8 \mathrm{~S}$ and the second internal transcribed spacer (ITS-2) ribosomal DNA sequences. Parasitol Int 2012, 61:497-500.

18. Testini G, Papini R, Lia RP, Parisi A, Dantas-Torres F, Traversa D, Otranto D: New insights into the morphology, molecular characterization and identification of Baylisascaris transfuga (Ascaridida, Ascarididae). Vet Parasitol 2011, 175:97-102.

19. Li Y, Niu L, Wang Q, Zhang Z, Chen Z, Gu X, Xie Y, Yan N, Wang S, Peng X, Yang G: Molecular characterization and phylogenetic analysis of ascarid nematodes from twenty-one species of captive wild mammals based on mitochondrial and nuclear sequences. Parasitology 2012:1-10.

20. Xie Y, Zhang Z, Wang C, Lan J, Li Y, Chen Z, Fu Y, Nie H, Yan N, Gu X, et al: Complete mitochondrial genomes of Baylisascaris schroederi, Baylisascaris ailuri and Baylisascaris transfuga from giant panda, red panda and polar bear. Gene 2011, 482:59-67.

21. Hartwich G: Über den Waschbärenspulwurm Ascaris procyonis Stefanski et Zarnowski 1951, und seine Stellung im System der Ascaroidea (Nematoda). Ceskoslovenská Parasitologie 1962, IX:239-256.

22. Sprent JF: Notes on Ascaris and Toxascaris, with a definition of Baylisascaris gen.nov. Parasitology 1968, 58:185-198.

23. Bowles J, Blair D, McManus DP: Genetic variants within the genus Echinococcus identified by mitochondrial DNA sequencing. Mol Biochem Parasitol 1992, 54:165-173.

24. Dereeper A, Guignon V, Blanc G, Audic S, Buffet S, Chevenet F, Dufayard JF, Guindon S, Lefort V, Lescot M, et al: Phylogeny.fr: robust phylogenetic analysis for the non-specialist. Nucleic Acids Res 2008, 36:W465-469.

25. Guindon S, Gascuel O: A simple, fast, and accurate algorithm to estimate large phylogenies by maximum likelihood. Syst Biol 2003, 52:696-704.

26. Dangoudoubiyam S, Vemulapalli R, Kazacos KR: PCR assays for detection of Baylisascaris procyonis eggs and larvae. J Parasitol 2009, 95:571-577.

27. H.D. Barton SMW: Phylogeography of striped skunks (Mephitis mephitis) in North America: Pleistocene dispersal and contemporary population structure. J Mammol 2012, 93:38-51.

doi:10.1186/1756-3305-6-124

Cite this article as: Franssen et al:: Molecular analysis of Baylisascaris columnaris revealed mitochondrial and nuclear polymorphisms. Parasites \& Vectors 2013 6:124

\section{Submit your next manuscript to BioMed Central and take full advantage of:}

- Convenient online submission

- Thorough peer review

- No space constraints or color figure charges

- Immediate publication on acceptance

- Inclusion in PubMed, CAS, Scopus and Google Scholar

- Research which is freely available for redistribution

Submit your manuscript at www.biomedcentral.com/submit
C) Biomed Central 